\title{
Mechanical, Thermal and Microstructural Characteristic of 3D Printed Polylactide Composites with Natural Fibers: Wood, Bamboo and Cork
}

\author{
Karolina E. Mazur ${ }^{1}$ (D) Aleksandra Borucka ${ }^{1} \cdot$ Paulina Kaczor $^{1} \cdot$ Szymon Gądek $^{1}$ (1) $\cdot$ Rafał Bogucki $^{1}$ (1) . \\ Dariusz Mirzewiński ${ }^{1}$ (D) Stanisław Kuciel ${ }^{1}$ (i)
}

Accepted: 30 November 2021 / Published online: 18 December 2021

(c) The Author(s) 2021

\begin{abstract}
In the study, polylactide-based (PLA) composites modified with natural particles (wood, bamboo, and cork) and with different levels of infilling $(100 \%, 80 \%$, and $60 \%)$ obtained by fused deposition modeling were tested. The effect of fiber type, infill level and crystallization rate on the mechanical properties were investigated by using tensile, flexural, and impact tests. The materials were subjected to mechanical tests carried out at 23 and $80^{\circ} \mathrm{C}$. Differential scanning calorimetry were employed to analyze crystallization behavior of composite. Furthermore, hydrothermal degradation was performed, and its effect on the properties was analyzed. The addition of natural fillers and different levels of infilling result in a similar level of reduction in the properties. However, the addition of natural fillers resulted in a slightly lower drop than the lowered infilling rate $-40 \%$ and $50 \%$ for tensile strength, respectively. Moreover, it was found that, composites made of PLA are more sensitive to high temperatures than to water. The decrease in Young's modulus of PLA at $80{ }^{\circ} \mathrm{C}$ was $90 \%$, while after 28 days of hydrodegradation $\sim 9 \%$. The addition of fibers reduced this decrease at elevated temperatures. Importantly, in the case of a brittle material such as PLA, the impact strength has been improved by $50 \%$ for composites with cork particles and other lignocellulosic composites remained at the same level as for resin. Generally, the thermal treatment of composites increased the degree of crystallinity of the materials, as reflected in the higher results of mechanical tests.
\end{abstract}

Keywords Biocomposite $\cdot$ High-temperature properties $\cdot$ Mechanical testing $\cdot 3$-D printing

\section{Introduction}

For more than three decades, there has been a substantial increase in interest in products developed using additive manufacturing (AM). Presently, AM has revolutionized the manufacturing industry as it enables rapid manufacturing of products while simultaneously reducing cost $[1,2]$. One of the most commonly used AM techniques is fused deposition modeling (FDM), which involves successive overlapping of layers of filaments; the production occurs without additional processing of the material, which allows reducing waste during production [3]. This technology has enabled to develop of prototypes with complex shapes, which is otherwise difficult to obtain by traditional techniques (injection molding) [4]. However, the production by AM requires a

Stanisław Kuciel

stask@mech.pk.edu.pl

1 Faculty of Materials Science and Physics, Cracow University of Technology, Warszawska 24, 31-155 Kraków, Poland continuous flow of materials, which can be disturbed during the filament application process. The lack of isotropy of products can significantly affect the mechanical properties of the tested materials; hence, new solutions to improve this method are being constantly investigated, such as nozzle and platform temperature, printing speed, the height of layer deposition, raster angle of infill pattern, build orientation, and addition of particles $[5,6]$. To date, many works have been published on the different levels of build orientation $\left(0^{\circ} / 90^{\circ}\right.$ or $\left.45^{\circ} / 45^{\circ}\right)$ with respect to each of $\mathrm{x}, \mathrm{y}$ and $\mathrm{z}$ axes [7]. Depending on the position of the filaments in relation to each other, the materials exhibit different properties, for example, materials with a $45^{\circ} / 45^{\circ}$ filament orientation have higher values of mechanical properties than those with a $0^{\circ} / 90^{\circ}$ filament system [8]. By optimizing the methods at the production level, it is possible to design a product with superior properties.

The refinement of AM led to the development of other fields of science and industry, such as materials engineering or chemical engineering and so on. The developed 
materials are perfected in order to obtain the most efficient production process. The most commonly used materials in FDM are thermoplastic polymers: acrylonitrile butadiene styrene, polyetherimide, polylactide (PLA), polycarbonate, and polymethylmethacrylate $[9,10]$. Because of concerns related to environmental pollution, PLA is gaining popularity as an alternative to synthetic polymer materials. PLA is a biodegradable, biocompatible polymeric material. This material is not only environmentally friendly, but it also has properties comparable to those of petrochemical polymers [11]. In addition, its melting temperature is relatively low, which makes its use in FDM cost-effective.

To change characteristics and additionally to reduce costs, composites with the addition of fibers or particles are often formed to reduce the production cost of the material, as is the case in traditional processing methods. Modifications of filaments can also be carried out in AM. It is reasonable to reinforce PLA with natural fillers containing lignocellulose such as wood, hemp, flax, etc. (the material remains $100 \%$ biodegradable). According to previous literature, the addition of natural fillers improves the stiffness of composites while reducing tensile or flexural strength [12]. However, the addition of lignocellulosic fillers to polymer composites generates a material with relatively high specific mechanical properties, while further reducing its cost.

Despite the many advantages of biodegradable polymers, during their processing and service life, some disadvantages appear. Biodegradable polymers have a faster water absorption capacity than petrochemical polymers. The penetration of water inside the biodegradable polymer composite affects its structural stability, leading to the breakage of the polymer chains [13]. This process is further accelerated by factors such as temperature, time of exposure to water, and structural modifications (blends or addition of fillers) [14]. These factors are mainly important for materials intended for medical applications (surgical screws, blood vessel prostheses, sutures, bone anastomoses, etc.). Because PLA is widely used in the field of medicine, it is crucial to conduct tests that measure the impact of the aquatic environment on PLAbased materials. Studies have shown that the level of water absorption increases and the value of mechanical properties decreases with increased duration of contact of composites with the aquatic environment. It was also observed that as the water temperature increases, the water absorption rate of the material increases, which causes a corresponding decrease in the value of mechanical properties [15]. Moreover, because fibers such as lignocellulose are hydrophilic in nature, the addition of fillers containing these fibers accelerates the process of water absorption into biodegradable composites [16]. To date, only a few studies have been published on the negative impact of water on the mechanical properties of 3D-printed polymer materials, including factors such as the degree of crystallization, degree of infilling, and addition of natural fillers [17].

In the present study, PLA-based composites reinforced with natural particles (wood, bamboo, and cork) were prepared using 3D printing. In addition, neat PLA materials with varying degrees of infills $(100 \%, 80 \%$, and $60 \%)$ were prepared. The novelty of the present study is the comparison of the impact of the addition of natural fillers and the different degree of infilling on the mechanical properties of composite materials in various operating environments such as ambient temperature, elevated temperature $\left(80^{\circ} \mathrm{C}\right)$, and immersion in saline solution at $38^{\circ} \mathrm{C}$. In addition, two states of composite materials were tested: semi-amorphous and crystalline. For this purpose, various mechanical tests (tensile strength, flexural, and impact) were conducted. In addition thermal analysis was performed to confirm the increase in the degree of crystallinity after the addition of the fibers and the heat treatment.

These studies are important for the development of the field of materials science and manufacturing techniques. To the best of the authors' knowledge, no direct comparison of all the above-mentioned aspects has been performed; thus, the present study may further expand the area of potential applications of these composites.

\section{Materials and Methods}

\section{Composites Filaments and Sample Preparation}

The filaments of neat PLA and PLA composites reinforced with 30 wt.\% of wood particles (W), 2 bamboo fibers (B), and cork (C) were provided by PriMat 3D sp. z o.o. (Poznan, Poland). The diameter of the filament was $1.75 \mathrm{~mm}$, regardless of filament type. Standard dumbbell samples in accordance with the ISO 20753 standard $(15 \times 4 \times 90)$ were produced by the FDM printer Zortrax M300 manufactured by Profound3D (Exton, PA, USA). The key printing parameters were the same for all tested samples and were the following: platform temperature: $50{ }^{\circ} \mathrm{C}$, nozzle temperature $210{ }^{\circ} \mathrm{C}$, printing speed: $60 \mathrm{~mm} / \mathrm{s}$, nozzle diameter: $0.4 \mathrm{~mm}$, infill pattern: linear, and layer height: $0.2 \mathrm{~mm}$. Additionally, in this study for composites modified with natural fillers the infill was adjusted to the maximum value (100\%) and for neat PLA from $100 \%, 80 \%$, and $60 \%$, and the raster angle was $45^{\circ} /-45^{\circ}$, regardless of type.

\section{Characterization of Composites}

\section{Morphological Study}

The fracture morphology of all the samples after the tensile test was evaluated by scanning electron microscopy (SEM) 
(JEOL JSM5510LV, Tokyo, Japan) operating at $20 \mathrm{kV}$ in a low vacuum. Prior to imaging, the specimens were goldsputtered by using an auto vacuum coater (Cressington, Watford, UK). This study gave information about filler distribution and showed the main characteristics of the filament orientation on breakthroughs.

\section{Differential Scanning Calorimetry}

Differential Scanning Calorimetry (DSC) of composites was performed on NETZSCH DSC 3500 Sirius (Selb, Germany) in a Nitrogen environment. Samples from the central part of injection molded samples of standard dumbbell-shape with mass of $10-15 \mathrm{mg}$ were heated from 20 to $200{ }^{\circ} \mathrm{C}$ at a heating rate of $10{ }^{\circ} \mathrm{C} / \mathrm{min}$ and $3 \mathrm{~min}$ isotherm, being cooled at the same rate. The whole process was carried out twice to eliminate the processing memory/history of the materials (the first heating-cooling cycle) and to define the thermal properties of the composites (the second heating-cooling cycle). An empty pan was used as a reference.

The degree of crystallinity of the samples was calculated according to equation:

$X_{c}=\frac{\Delta H_{m}-\Delta H_{c c}}{(1-\varphi) \Delta H_{m}^{o}}$

where: $\Delta H_{m}$ is melting enthalpy $(\mathrm{J} / \mathrm{g}), \varphi$ is weight $\%$ of the filler in composite (\%) and $\Delta H_{m}^{o}$ is the mean melting enthalpy of $100 \%$ crystalline PLA at $93 \mathrm{~J} / \mathrm{g}$ [18].

\section{Physico-Mechanical Tests}

Density was obtained by measuring dimensions and mass using the RADWAG WAS 220/X (Radom, Poland) electronic analytical balance following the immersion method according to the ISO:1183-1 standard.

In order to study mechanical properties tensile, flexural and impact tests were performed. The tensile (ISO:527 standard) and flexural (ISO:178 standard) properties were studied by using the universal MTS Criterion Model 43 testing machine (Eden Prairie, MN USA) [19, 20]. The displacement rate was fixed to $10 \mathrm{~mm} / \mathrm{min}$ and $5 \mathrm{~mm} / \mathrm{min}$ for tensile tests and three-point flexural tests, respectively. The impact strength was measured by the Charpy test using by Zwick/Roell MTS-SP testing machine (Ulm, Germany) on un-notched samples according to the ISO:179 standard. The applied energy on nu-notched samples was $1.5 \mathrm{~J}$.

All mechanical tests were performed under various testing conditions:

- at ambient temperature $\left(+23{ }^{\circ} \mathrm{C} \pm 2\right)$, which was reflected in the control group;
- at elevated temperature $\left(+80{ }^{\circ} \mathrm{C}\right)$ in the temperature chamber (Instron), to assess the impact of high temperatures. Before tests the samples were conditioned for $30 \mathrm{~min}$ at $+80^{\circ} \mathrm{C}$.

Additionally, samples for mechanical tests were heat-treated to increase the degree of crystallinity. In this process, samples were placed in a furnace at $85^{\circ} \mathrm{C}$ for $60 \mathrm{~min}$ between two glass plates to prevent their deformation. This process is justified in the case of PLA because it has a semi-amorphous state during production. Upon heating the material above cold crystallization temperature and its slow cooling, a crystalline phase material is formed.

\section{Hydrolytic Degradation}

For the calculation of water absorption, samples were immersed into the saline solution (distilled water with 0.9 wt. $\%$ of $\mathrm{NaCl}$ ) at $38^{\circ} \mathrm{C}$ (physiological temperature) to create a human body environment. The measurements were carried out in accordance with the modified ISO:62 standard, which was adopted as a hydrothermal aging environment, modifying the temperature and water specifications to the desire aging condition. The samples were kept in saline for 1,7 , and 28 days. The water absorption rate of the samples was calculated by the following equation:

$W \%=\frac{\left(W_{t}-W_{0}\right)}{\left(W_{0}\right)} \times 100$

where, $\mathrm{W} \%$ is percentage of absorbed solution, $\mathrm{W}_{\mathrm{t}}$ stands for the instantaneous weight of the sample and $\mathrm{W}_{0}$ for the initial weight of the sample.

To determine the influence of water uptake on the basic mechanical properties of the specimens which were incubated for 28 days in water, a tensile test was performed. This study was conducted to consider two conditions: physiological temperature and water absorption. Before tests, after taking them out of the solution, the samples were dried with paper towel.

\section{Results}

\section{Microstructure}

Figures 1 and 2 show the fractured surface of the composites after the tensile test. As shown in the figure, the addition of natural fillers changed the characteristic of the breakthrough from ductile to fragile. As described below, the decrease in the values of mechanical properties for composites with $80 \%$ and $60 \%$ infilling was caused by a lack of material continuity and gaps between the applied 

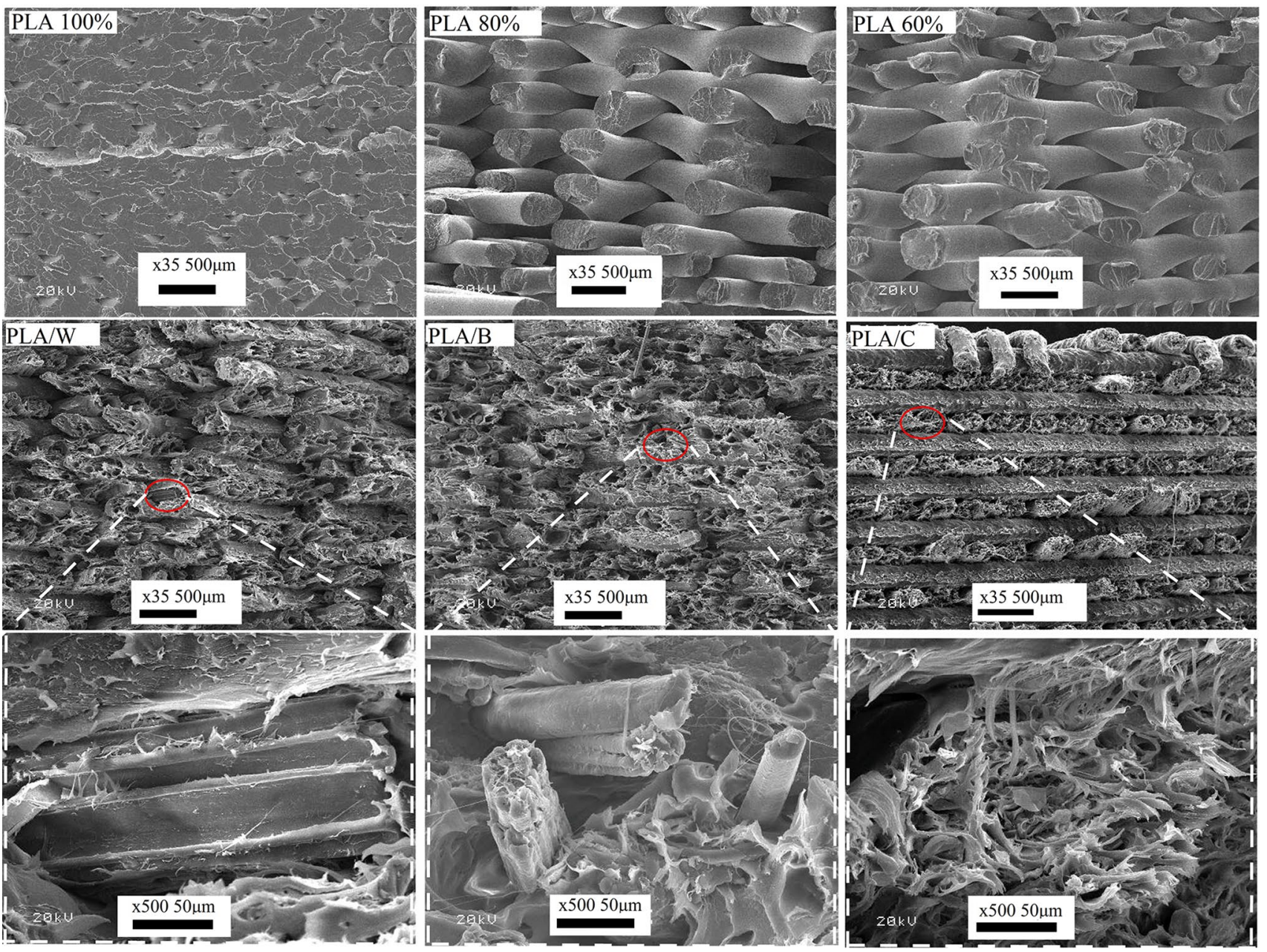

Fig. 1 SEM images of fracture morphology for tested materials before thermal treatment

filaments (higher porosity of materials) what can be seen in Figs. 1 and 2. Furthermore, it can be seen that each natural fiber used in the present study has a different structure. Wood fibers are the widest, and the width reaches approximately $800 \mu \mathrm{m}$; additionally, the adhesion between the matrix and the fiber is poor which additionally contributed to the reduction of mechanical properties. Bamboo fibers are the longest, and their filamentary structure can be observed in the figure. Black rings around the bamboo fibers occur, which indicate poor adhesion and deformation. However, because of the length of bamboo fibers, the value of the mechanical properties of composites with these fibers are the highest compared to those of the other tested materials [21]. It is related to the dependence that the longer the fiber the greater the reinforcement effect in the polymer matrix. This analysis shows that in the case of 3D printed materials, the fillers should be subjected to additional processing or a compatibilizer should be used in order to increase the adhesion fillers/matrix and filament/ filament.

\section{DSC}

Figure 3 shows the thermograms obtained during the DSC. Characteristic temperatures were observed for materials without heat treatment in the first heating cycle (Fig. 3a). The appearance of the peak around $67.1-69{ }^{\circ} \mathrm{C}$ indicates the typical glass transition temperature $\left(\mathrm{T}_{\mathrm{g}}\right)$ which is responsible for the relaxation of the PLA amorphous domains [22]. Another characteristic temperature observed on the thermogram was the cold crystallization $\left(\mathrm{T}_{\mathrm{cc}}\right)$ temperature in the range $102-103.2{ }^{\circ} \mathrm{C}$. However, the addition of natural fillers did not significantly change the value of these temperatures. The highest $T_{g}$ changes were observed for composites with bamboo and cork fibers-a decrease by 1.1 and 1.8. As for $\mathrm{T}_{\mathrm{cc}}$ and $\mathrm{T}_{\mathrm{m}}$, the values were at a similar level. A different situation was observed for composites subjected to previous thermal treatment. As long as they have $\mathrm{T}_{\mathrm{g}}$ and $\mathrm{T}_{\mathrm{m}}$, for these materials the exothermic peak $\mathrm{T}_{\mathrm{cc}}$ is not observed, which is responsible for the crystallization of the material during heating for aliphatic polyesters. This situation confirms 

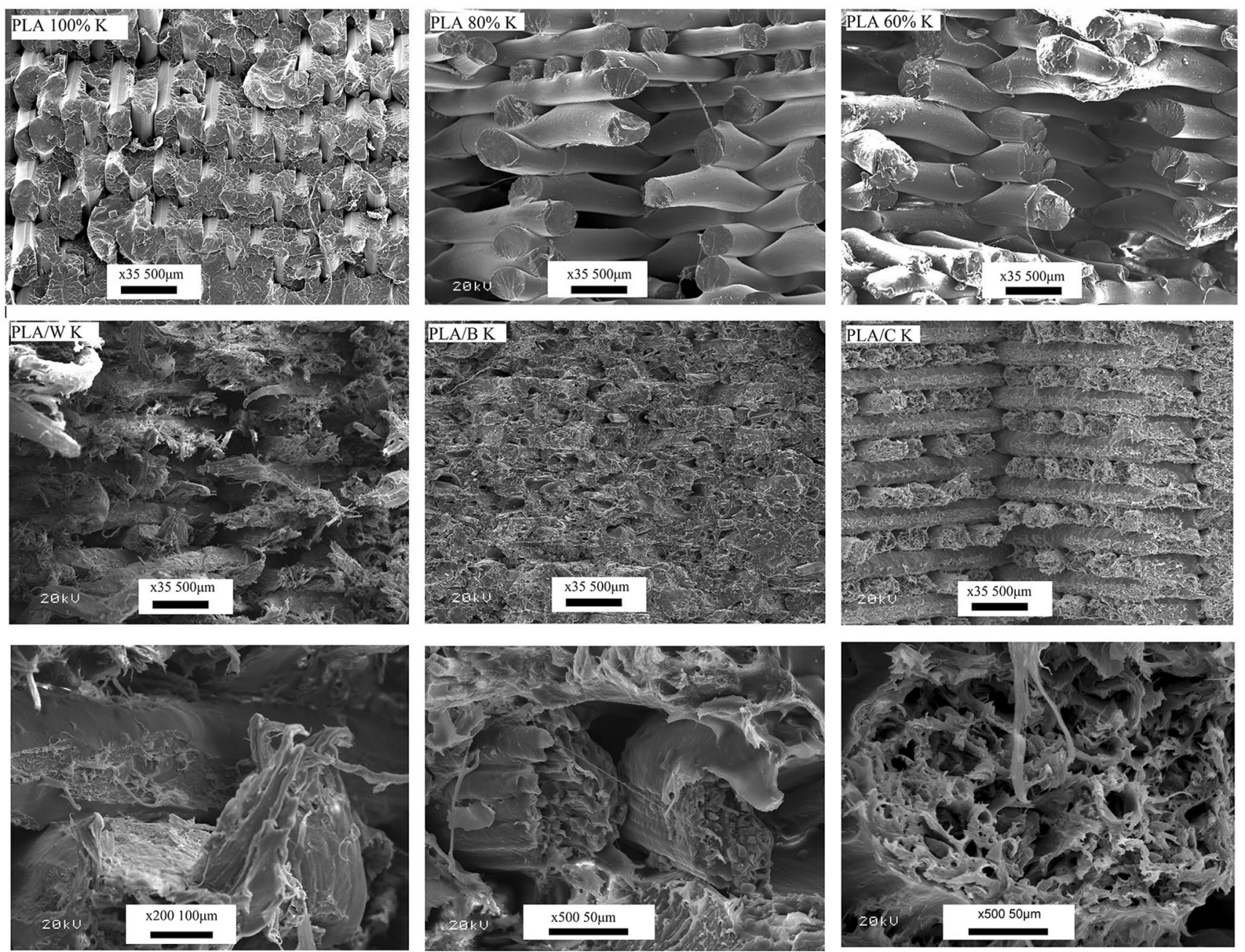

Fig. 2 SEM images of fracture morphology for tested materials after thermal treatment

that the applied heat treatment process led to an increase in the degree of crystallinity, which also confirms the higher degree of crystallinity for the materials after the treatment. A similar situation was observed by Papadopoulos et al. who associated the absence of the $T_{c c}$ peak with the rigid amorphous fraction [23].

The addition of natural fillers only slightly improved the degree of crystallinity of the composites, while a significant improvement of this value was achieved after heat treatment. The highest increase was achieved for neat PLA (16-fold improvement), while the lowest for PLA/Wc. The results of thermal analysis perfectly correspond with the results of mechanical tests - the higher the degree of crystallinity, the higher the mechanical properties.

\section{Physico-Mechanical Properties}

Table 1 summarizes the used abbreviations, density, and specific properties of PLA composites. It seems obvious that with a decrease in the degree of filling in materials, its density decreases. This relationship was also observed in these studies, where the following trend has been noticed: PLA $100 \%>$ PLA $80 \%>$ PLA60\% and PLA/C $>$ PLA/W $>$ PLA/B. It should be emphasized that the addition of fibers had an equal or greater impact on the decrease in density than the lower degree of PLA filling. The density of the tested composites decreased with the addition of natural fibers due to the closed morphology of lignocellulosic fibers and its lower density compared to the matrix [24]. In addition, as can be seen in the SEM pictures (Figs. 1, 2 ), the composites are characterized by insufficient adhesion between the fiber and the matrix, which increased the number of voids in the material-higher porosity. The effect of this phenomenon is a decrease in the volume fraction of neat polymer and thus decrease the density of composites. Moreover, AM itself causes an increase in discontinuities between individual layers, and the extra inclusions increase them even more. However, it should be emphasized that 

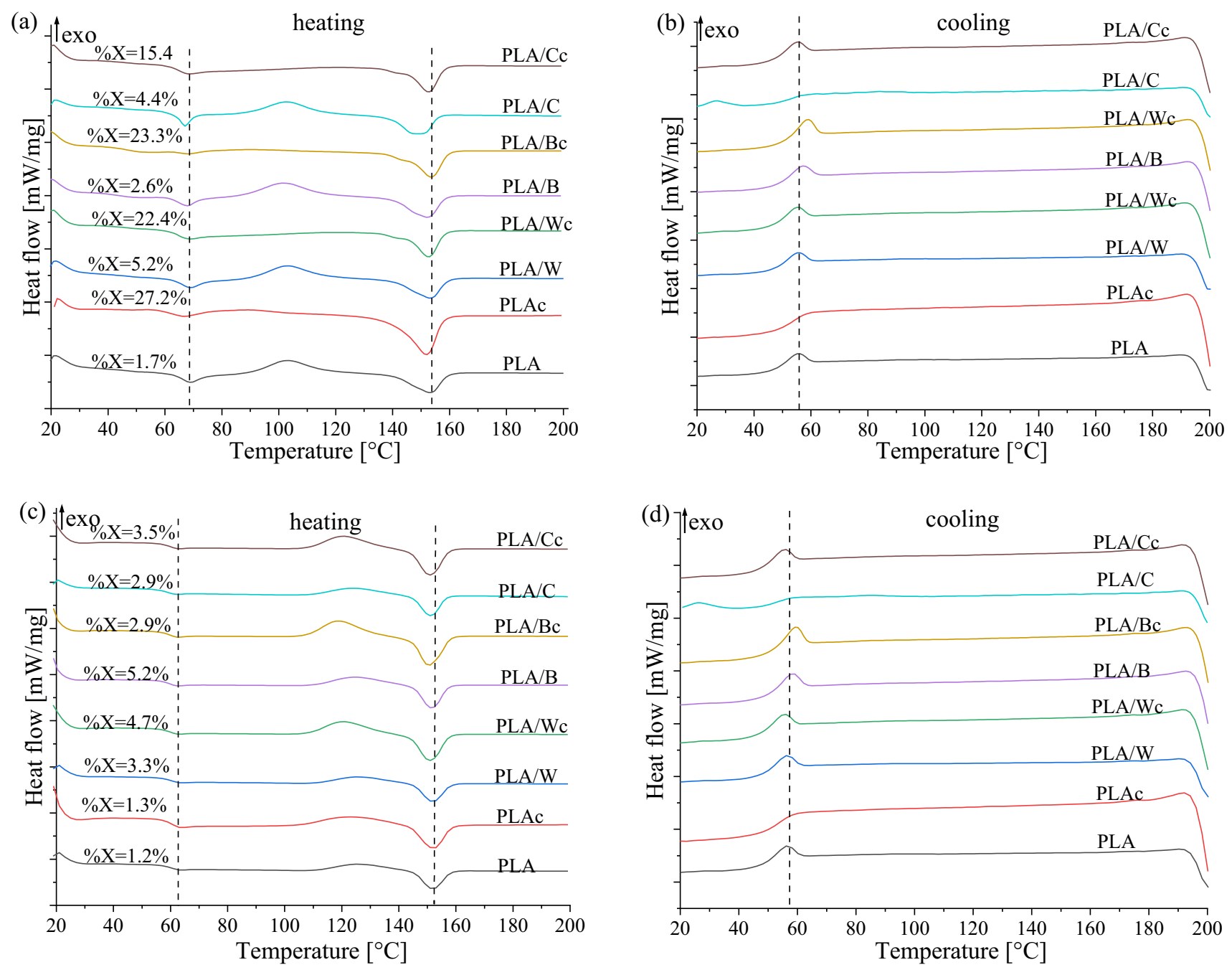

Fig. 3 DSC thermograms of PLA and its composites: a first heating stage, $\mathbf{b}$ first cooling stage, $\mathbf{c}$ second heating stage, $\mathbf{d}$ second cooling stage

Table 1 Abbreviations of tested composites, density, and specific modulus of PLA composites

\begin{tabular}{llll}
\hline Sample & Abbreviation & Density $\left(\mathrm{g} / \mathrm{cm}^{3}\right)$ & $\begin{array}{l}\text { Specific modulus } \\
{\left[\mathrm{MPa} /\left(\mathrm{kg} / \mathrm{m}^{3}\right)\right]}\end{array}$ \\
\hline Polylactide with 100\% infill & PLA100\% & $1.23 \pm 0.01$ & $3.02 \pm 0.09$ \\
Polylactide with 80\% infill & PLA80\% & $1.22 \pm 0.01$ & $1.30 \pm 0.06$ \\
Polylactide with 60\% infill & PLA60\% & $1.19 \pm 0.02$ & $1.24 \pm 0.07$ \\
Polylactide with wood fibers & PLA/W & $1.17 \pm 0.01$ & $1.89 \pm 0.09$ \\
Polylactide with bamboo fibers & PLA/B & $1.13 \pm 0.01$ & $2.07 \pm 0.14$ \\
Polylactide with cork particles & PLA/C & $1.19 \pm 0.02$ & $1.55 \pm 0.08$ \\
\hline
\end{tabular}

these defects did not affect the repeatability of the results, as the standard deviation was less than $5 \%$.

In the case of composites dedicated engineering applications, not only a single property but a ratio of two dependencies is taken into account during the selection of the material. Because today's market expects materials of high stiffness and relatively low weight, in this work the ratio of Young's modulus value to density was determined. The addition of natural fillers decreased the specific values of the tested composites. The highest specific modulus was observed for neat PLA (3.02 MPa/ $\left(\mathrm{kg} / \mathrm{m}^{3}\right)$; density $1.23 \mathrm{~g} /$ $\left.\mathrm{cm}^{3}\right)$; however, a slightly lower value $\left(2.07 \mathrm{MPa} /\left(\mathrm{kg} / \mathrm{m}^{3}\right)\right.$ ) was recorded for PLA/B where the lowest density was met $\left(1.13 \mathrm{~g} / \mathrm{cm}^{3}\right)$. The decrease in the specific properties for 

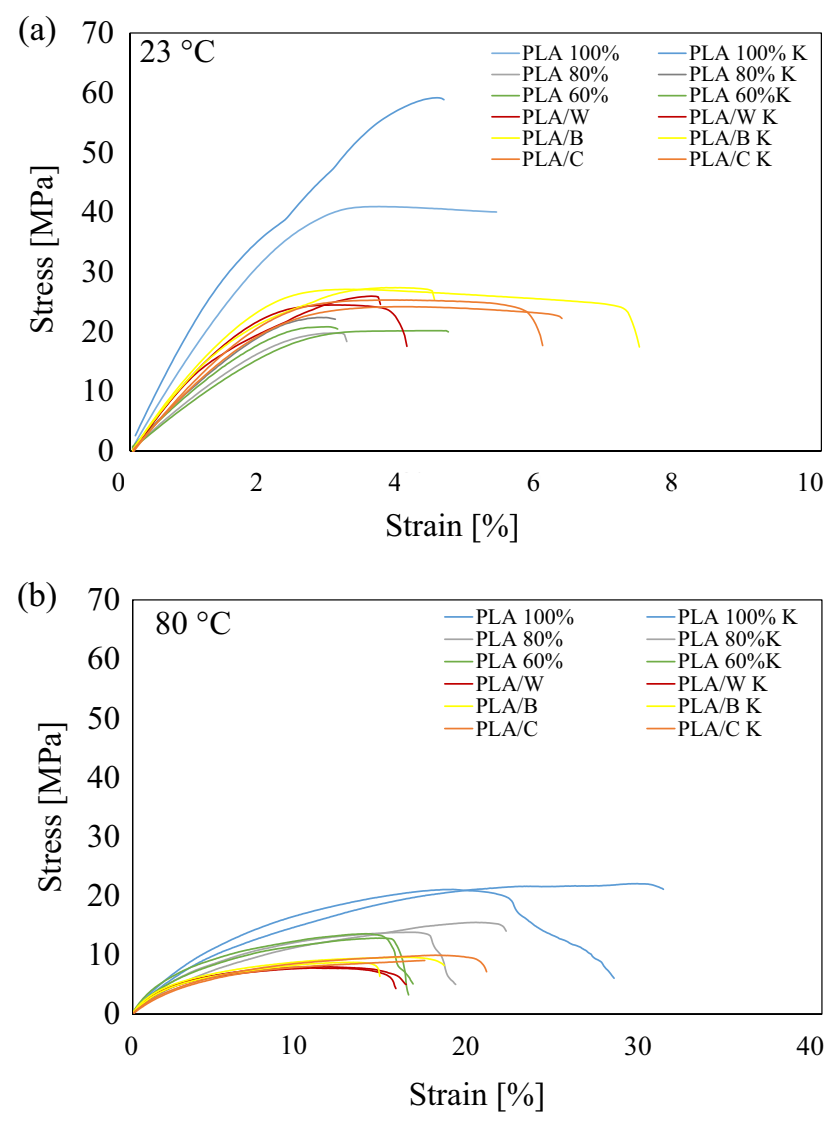

Fig. 4 Tensile stress-strain curves of PLA composites with different infill and fillers a at $23{ }^{\circ} \mathrm{C}$ and $\mathbf{b} 80{ }^{\circ} \mathrm{C}$

composites with the addition of lignocellulosic fibers was lower than $50 \%$ and amounted to PLA/B-31\%; PLA/W$37 \%$ and PLA/C - 48\%. Despite quite similar density values of composites filled with natural fibers and with vary infilling levels, PLA $80 \%$ and $60 \%$ showed a decrease of more than double in specific modulus (difference in density $>8 \%$ ). In this case, the result was affected by a significant decrease in Young's modulus, caused by discontinuities in the material that generated additional stress concentrations areas.

\section{Tensile Properties}

The selected stress-strain curves for the tested materials are shown in Fig. 4 (a) composites tested at ambient temperature and (b) at elevated temperature $\left(80^{\circ} \mathrm{C}\right)$. At $23{ }^{\circ} \mathrm{C}$ in the first stage, the strain was proportional to the stress (Hooke's law) up to the yield stress. At both $23{ }^{\circ} \mathrm{C}$ and $80{ }^{\circ} \mathrm{C}$, neat PLA $100 \%$ showed the highest stress. At $80{ }^{\circ} \mathrm{C}$, a significant increase in elongation was observed up to over $30 \%$ (PLA 100\%), and the stress decreased by more than half compared to that at ambient temperature. This effect was caused by the test temperature above $\mathrm{T}_{\mathrm{g}}$ of PLA $\left(\sim 60{ }^{\circ} \mathrm{C}\right)$ where the amorphous regions experience the transition from the rigid state (solid) to a more flexible (rubbery) state [25]. With an increase in temperature, the ability to move the polymer chain increased, which resulted in significant elongation and reduction in strength values. At high temperatures, the polymer chains are reorganized and arranged along with the load. Consequently, the material became more susceptible to plastic deformation [26].

Natural fillers had a more negative effect on the values of mechanical properties than filling levels at $80^{\circ} \mathrm{C}$. This relationship was most likely caused by partial crystallization of neat PLA during the test (higher crystallization rate, higher mechanical properties). Neat semi-amorphous PLA (immediately after production) has a greater ability to form crystals during the temperature annealing process than composites with natural fibers, as reported in the literature [27]. In addition, as shown in Fig. 4b, not so significant differences were noted between neat PLA after heat treatment and neat PLA without heat treatment as observed at $23{ }^{\circ} \mathrm{C}\left(26 \%\right.$ decrease at $80{ }^{\circ} \mathrm{C}$ and $59 \%$ decrease at $23{ }^{\circ} \mathrm{C}$ ). This finding also confirms the possibility of the crystallization process for semi-amorphous samples during tests conducted at $80{ }^{\circ} \mathrm{C}$.

To better discuss the results Table 2 presents the selected data obtained during the static tensile test (tensile strength, Young's modulus, and strain at break). The reduction in both the level of infilling and the addition of natural fillers caused a significant decrease in the values of mechanical properties, regardless of the test temperature. Deterioration of tensile strength for all modified materials was at a similar level and the obtained values were in the range -19.2 to $26.3 \mathrm{MPa}$ (ambient temperature) and -8.2 to $21.1 \mathrm{MPa}$ (elevated temperature). Both the addition of natural fibers and the reduction in the degree of infilling of composites reduced the value of tensile strength by approximately $50 \%$. The highest decrease was noted for PLA $60-55 \%$ while the lowest for PLA/B-39\% (ambient temperature).

In general, three factors have an impact on the results obtained during the tensile tests of fiber-reinforced composites: initial fiber/matrix strength, fiber length, and fiber/ matrix adhesion. In the case of fiber-reinforced composites, it is expected that the fibers which usually have a higher stiffness than the polymer matrix will carry the load applied to the matrix. However, the condition of sufficient fiber/matrix adhesion must be met. As was already reported, the addition of unmodified natural fibers is leading to a decrease in strength [28, 29]. In this study, insufficient fiber/matrix adhesion confirmed by SEM (Figs. 1,2) and empty spaces in the material had a negative effect on the mechanical properties. The first reason is due to the hydrophilic nature of the fibers and the hydrophobic nature of the matrix, which prevents the formation of strong bonds between the components. 
Table 2 Tensile properties of PLA composites

\begin{tabular}{|c|c|c|c|c|c|c|c|c|}
\hline \multirow[t]{2}{*}{ Tensile properties } & \multirow[t]{2}{*}{ Condition } & \multirow{2}{*}{$\begin{array}{l}\text { Thermal } \\
\text { treatment }\end{array}$} & \multicolumn{6}{|l|}{ Composites } \\
\hline & & & $\begin{array}{l}\text { PLA } \\
100 \%\end{array}$ & $\begin{array}{l}\text { PLA } \\
80 \%\end{array}$ & $\begin{array}{l}\text { PLA } \\
60 \%\end{array}$ & PLA/W & PLA/B & PLA/C \\
\hline \multirow[t]{4}{*}{ Tensile strength $(\mathrm{MPa})$} & \multirow[t]{2}{*}{$+23^{\circ} \mathrm{C}$} & NO & $42.9 \pm 3.9$ & $20.6 \pm 2.6$ & $19.2 \pm 1.4$ & $24.7 \pm 0.5$ & $26.3 \pm 0.6$ & $24.1 \pm 1.1$ \\
\hline & & YES & $58.5 \pm 0.7$ & $21.6 \pm 1.0$ & $20.7 \pm 0.9$ & $25.2 \pm 0.7$ & $27.3 \pm 0.2$ & $25.1 \pm 0.4$ \\
\hline & \multirow[t]{2}{*}{$+80^{\circ} \mathrm{C}$} & NO & $21.1 \pm 0.6$ & $15.6 \pm 0.6$ & $12.9 \pm 0.8$ & $8.2 \pm 0.7$ & $9.6 \pm 0.6$ & $9.9 \pm 0.5$ \\
\hline & & YES & $23.9 \pm 2.5$ & $14.2 \pm 0.5$ & $13.5 \pm 0.6$ & $7.9 \pm 0.5$ & $8.4 \pm 0.6$ & $9.3 \pm 0.7$ \\
\hline \multirow[t]{4}{*}{ Young's modulus (MPa) } & \multirow[t]{2}{*}{$+23^{\circ} \mathrm{C}$} & NO & $3742 \pm 74$ & $1585 \pm 95$ & $1470 \pm 87$ & $2213 \pm 26$ & $2334 \pm 112$ & $1844 \pm 51$ \\
\hline & & YES & $3926 \pm 100$ & $1711 \pm 94$ & $1524 \pm 45$ & $2296 \pm 27$ & $2359 \pm 51$ & $2021 \pm 18$ \\
\hline & \multirow[t]{2}{*}{$+80^{\circ} \mathrm{C}$} & NO & $392 \pm 89$ & $330 \pm 16$ & $292 \pm 30$ & $325 \pm 7$ & $386 \pm 17$ & $247 \pm 7$ \\
\hline & & YES & $366 \pm 21$ & $358 \pm 25$ & $332 \pm 70$ & $322 \pm 10$ & $302 \pm 8$ & $211 \pm 12$ \\
\hline \multirow[t]{4}{*}{ Elongation at break (\%) } & \multirow[t]{2}{*}{$+23{ }^{\circ} \mathrm{C}$} & NO & $6.4 \pm 0.22$ & $3.4 \pm 0.15$ & $4.6 \pm 0.25$ & $3.6 \pm 0.09$ & $7.1 \pm 0.32$ & $6.4 \pm 0.36$ \\
\hline & & YES & $2.6 \pm 0.10$ & $2.7 \pm 0.11$ & $2.6 \pm 0.10$ & $3.3 \pm 0.10$ & $4.8 \pm 0.16$ & $5.7 \pm 0.29$ \\
\hline & \multirow[t]{2}{*}{$+80^{\circ} \mathrm{C}$} & NO & $30.1 \pm 1.26$ & $17.2 \pm 0.87$ & $14.5 \pm 0.65$ & $14.1 \pm 0.56$ & $13.7 \pm 0.57$ & $21.3 \pm 1.15$ \\
\hline & & YES & $22.4 \pm 1.21$ & $21.1 \pm 1.02$ & $25.3 \pm 1.09$ & $15.7 \pm 0.55$ & $18.8 \pm 0.74$ & $25.5 \pm 0.98$ \\
\hline
\end{tabular}

Furthermore, during the FDM process, the incorporation of fibers creates higher empty spaces between the applied layers [30].

The modification of PLA also had a negative effect on the stiffness of the tested composites. Lowering the degree of filling in composites had a more negative effect on Young's modulus values than the addition of natural fibers. Moreover, in the case of Young's modulus, the differences in decreases in the values to neat PLA were higher than in the case of tensile strength. The following decrease was observed: PLA/B $(38 \%)>$ PLA/W $(41 \%)>$ PLA/C $(51 \%)>$ PLA $80 \%$ $(58 \%)>$ PLA60\% (61\%).

As PLA is known to occur in various forms from amorphous to the crystalline phase, the more the amount of the crystalline phase, the higher is the value of the mechanical properties of materials. Consequently, various methods have been used to increase the degree of crystallinity: the addition of fillers or heat treatment [31]. Therefore, heat-treated materials were also considered in the study to achieve higher mechanical results.

As shown by previous research of the authors of the presented work, the PLA after annealing (heat treatment) increases the amount of the crystalline phase and thus increases the value of the mechanical properties [32]. The highest improvement in properties was recorded for neat PLA (over 35\% for tensile strength). After the thermal treatment, neat 3D printed PLA had higher values of mechanical properties than those of PLA produced by traditional methods (injection molding) [33]. The addition of natural fibers did not significantly change the tensile strength after crystallization (max. improvement was 10\%). This shows that despite the increase in the degree of crystallization, the negative effect of natural fillers persists. This occurs due to the formation of stresses at the borders of the matrix and filler. Moreover, this may be because of increasing loss of adhesion due to shrinkage of the PLA matrix during crystallization, which could increase the lack of fiber/matrix adhesion.

In addition, elongation at break after crystallization was reduced more than doubled. The reduction in elongation indicates an increase in material stiffness, which is confirmed by the improvement in Young's modulus value. All tested materials showed an increase in the modulus of elasticity for heat-treated materials. However, it should be noted that the higher improvement for tensile strength than for Young's modulus was registered.

Negative effects of elevated test temperatures were observed in the present study. Neat PLA showed a decrease in tensile strength by approximately $50 \%$, while composites with the addition of fibers recorded a decrease by 3 times (from $24.7 \pm 0.5 \mathrm{MPa}$ to $7.9 \pm 0.5 \mathrm{MPa}$ for PLA/W). The decrease in Young's modulus was even higher, with approximately $90 \%$ for neat PLA and approximately $80 \%$ for composites. Because of the relatively low $\mathrm{T}_{\mathrm{g}}$, the values of the mechanical properties of PLA decreased drastically as the material became more plastic. At high test temperatures, the increase in the crystalline phase did not affect the results.

The results show that both the introduction of natural fillers and the reduction of the filling density have a similar effect on the mechanical properties of 3D printed polymer composites. Although a decrease in mechanical properties was observed, it should be noted that the results are comparable with other commonly used composites (polypropylene, polyethylene, etc.) produced by injection molding [34, 34]. In all these cases, the main advantage of the produced composites is the reduction of polymer matrix content, which constitutes both an economic and an environmental benefit. In addition, the use of bio-based materials in combination 

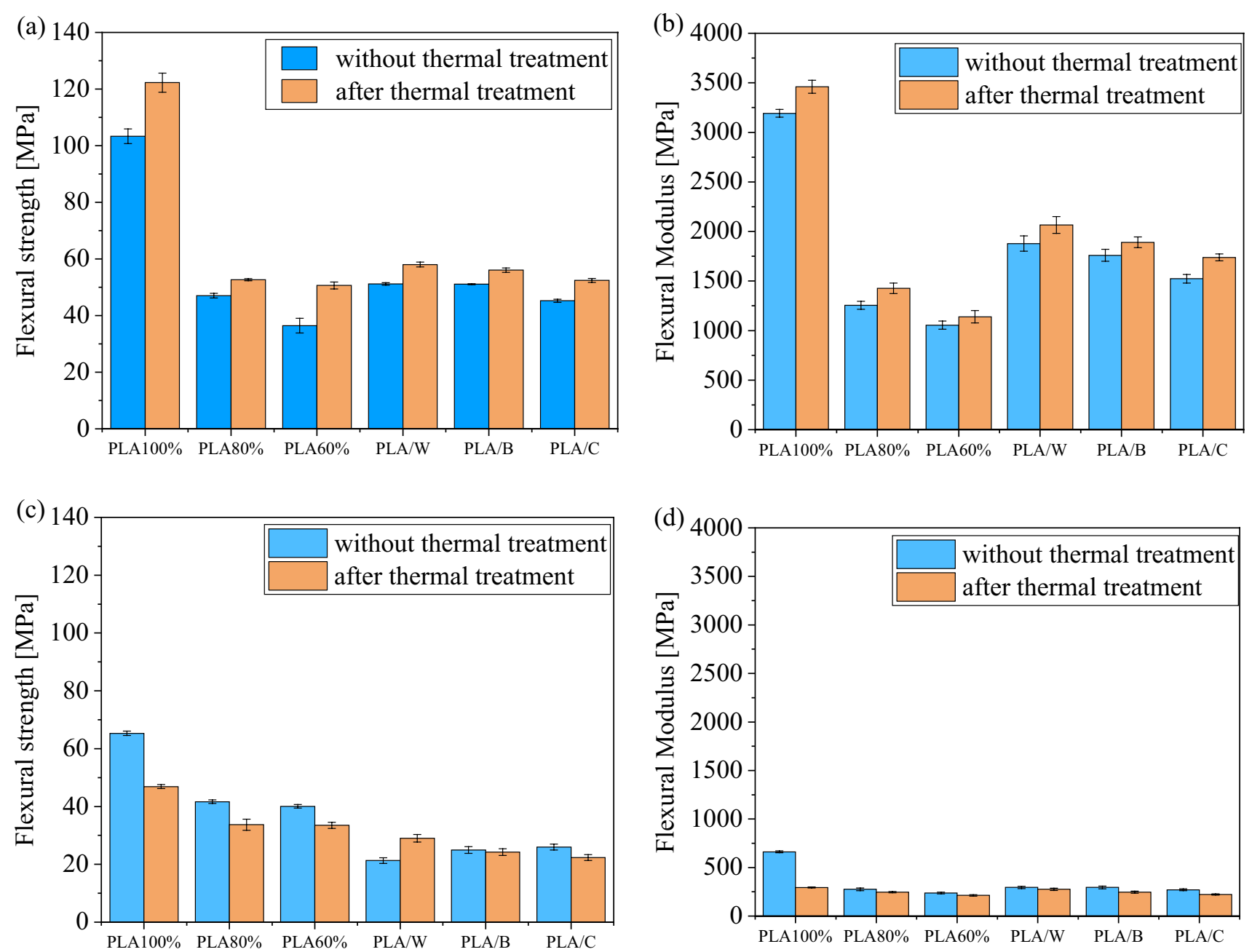

Fig. 5 Flexural properties of PLA and its composites: a flexural strength at $23{ }^{\circ} \mathrm{C}, \mathbf{b}$ flexural modulus at $23{ }^{\circ} \mathrm{C}$, $\mathbf{c}$ flexural strength at $80{ }^{\circ} \mathrm{C}$ and $\mathbf{d}$ flexural modulus at $80{ }^{\circ} \mathrm{C}$

with 3D printing techniques (waste reduction) further increases the above-mentioned benefits.

\section{Flexural Properties}

The properties obtained during the three-point flexural test are very important, because they combine different stresses, i.e. compression and tension. Phenomena occurring during the flexural test depends on the position: the upper layer is subjected to compression while the lower layer to tension. Therefore, in the flexural test, good fiber/matrix adhesion is not as significant as the fiber orientation. The more parallel the fibers are arranged in the matrix, the higher the flexural properties.

Similar relationships as in the tensile test were noticed in the three-point flexural test (Fig. 5). However, the results obtained during the flexural test are twice as high as during the tensile test. This fact is related to the aforementioned mechanisms that occur during tests. In addition, as can be seen in the SEM pictures (Figs. 1,2), the fibers are distributed mostly parallel in the matrix, which means that the fibers are more resistant to the applied load.

For both composites with reduced infilling content and with the addition of natural fillers, the properties of flexural strength and flexural modulus have decreased. No significant differences were observed in the results of flexural strength composites with natural fillers (45.3 MPa- 51.2 MPa). However, their decrease compared to neat PLA was about 50\%. A similar situation occurred in flexural modulus. The decrease in properties is caused by the increase in the porosity of the composites produced by inadequate interfacial bonding. The results obtained coincide with the results of the work of composites with natural fillers obtained by FDM [30].

A higher decrease in properties was noted for composites with a lower degree of filling, for flexural modulus it was up to 3 times lower. At elevated temperatures, the 
Table 3 Impact strength of PLA composites with vary infills and fillers

\begin{tabular}{llrrrrr}
\hline Impact strength $\left(\mathrm{kJ} / \mathrm{m}^{2}\right)$ & & & & & \\
\hline Samples & PLA100\% & PLA80\% & PLA60\% & PLA/W & \multicolumn{1}{c}{ PLA/B } & PLA/C \\
\hline Without thermal treatment & $10.4^{ \pm 0.4}$ & $7.5^{ \pm 0.6}$ & $7.9^{ \pm 0.2}$ & $9.4^{ \pm 0.9}$ & $9.1^{ \pm 0.2}$ & $22.3^{ \pm 0.7}$ \\
After thermal treatment & $19.6^{ \pm 0.7}$ & $10.7^{ \pm 0.2}$ & $10.4^{ \pm 0.4}$ & $12.4^{ \pm 0.9}$ & $12.3^{ \pm 0.5}$ & $25.0^{ \pm 0.7}$ \\
\hline
\end{tabular}
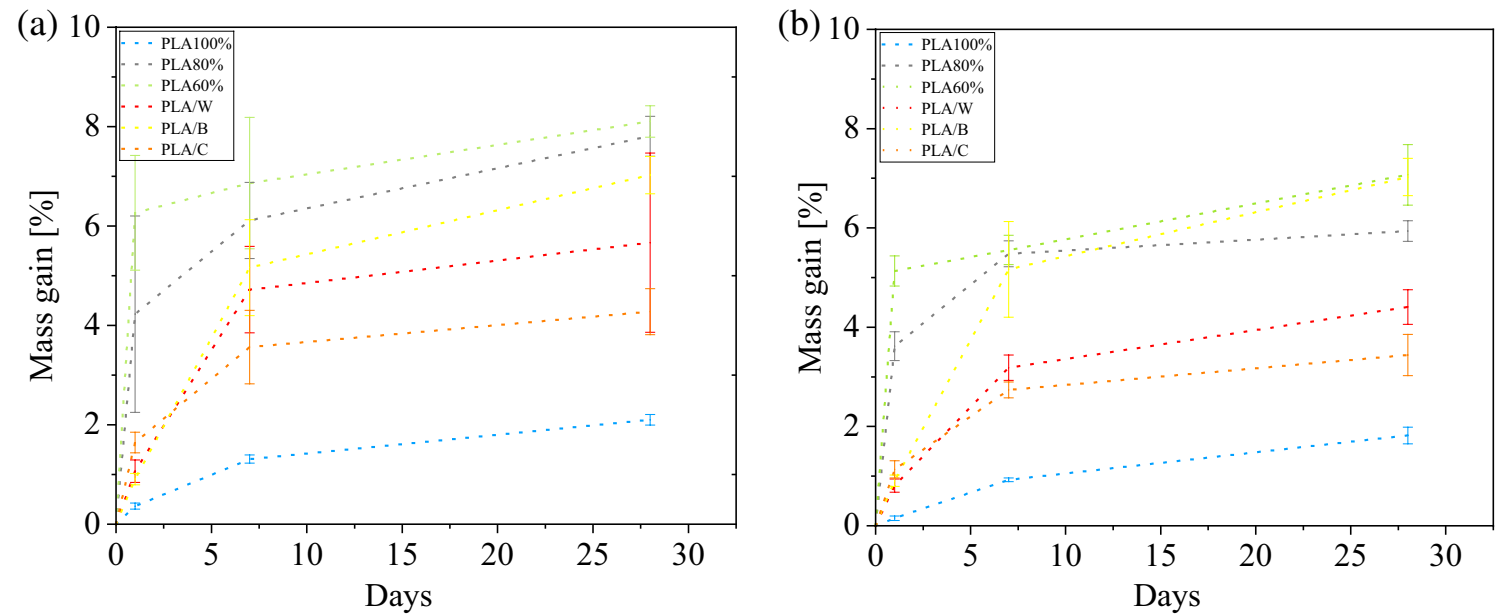

Fig. 6 Water absorption of PLA composites with vary infills and fillers; $\mathbf{a}$ before thermal treatment and $\mathbf{b}$ after thermal treatment

decrease in all values remained at the same level for each of the composites. This indicates a greater influence of temperature on mechanical values than the amount of filling or type of filler.

The influence of the degree of crystallization of composites is also visible. Along with the increase in the degree of crystallization, the mechanical properties increased at $23{ }^{\circ} \mathrm{C}$, the highest differences can be seen in the case of neat PLA, the increase was about $20 \%$. At $80{ }^{\circ} \mathrm{C}$ composites reported lower properties after heat treatment than before. As with tensile properties, this is due to the formation of crystallites when tested at high temperatures.

\section{Impact Properties}

For fiber-reinforced composites during loading, the impact strength component is affected by fiber pull out or breaking of fibers. As reported in the literature, composites with longer fibers that pull out have higher impact strength values, while composites with short fibers have significantly reduced impact strength values [36]. In composites with the same fiber content, shorter fibers occur more than long ones, which implies means that short fibers generate more stress concentration areas at the fiber ends. Impact strength results for composites were presented in Table 3 .
In the present study, composites with the addition of wood and bamboo fibers showed similar values of mechanical properties as those of neat PLA; this finding indicates no negative impact of natural fibers on the impact properties. According to the literature, the addition of natural fillers to polymer composites results in a reduction of impact strength [37]. It should be emphasized that in this paper the results of impact strength are higher or at a similar level as the matrix. The impact strength of PLA/C composites was improved by more than twice (from 10.87 to $22.1 \mathrm{~kJ} / \mathrm{m}^{2}$ ).

Similar to the values of properties obtained during the tensile and flexural tests, the impact strength values increased after thermal treatment. The most obvious gain effect caused by the increase in the amount of the crystalline phase was noted for neat PLA $100 \%$.

The reduction in the degree of filling decreased the impact strength value by approximately $30 \%$ for both PLA $80 \%$ and $60 \%$; however, no significant differences in the results were noted between the different levels of filling (80\% and 60\%).

\section{Influence of Hydrolytic Degradation on Mechanical Properties}

In the field of biodegradable polymers, hydrolytic degradation and its impact on changing mechanical properties of materials have a very important role. Several factors 
determine water absorption of composite materials: type of polymer matrix, type, and content of fillers, adhesion matrix/ filler, and test temperature [38]. In this study synergic effect of water and temperature was studied. Figure 6 shows the change in weight of the composites during immersion in saline at $38^{\circ} \mathrm{C}$.

As observed for modified composites, the highest mass increase occurred in the first stage; subsequently, saturation occurred after 7 days (when the daily weight gain of the samples was less than $0.01 \%$ ), and the mass remained constant for up to 28 days.

The mechanism of water absorption in these studies is not in accordance with Fick's law of diffusion. There is no threestage sorption course distinguished: rapid increase in the first phase and sorption release followed by saturation [39]. This is most likely caused by the capillarity phenomena, which was caused by fiber swelling. In addition, as other researchers indicate, this phenomenon may be associated with the leaching of polymer particles, which leads to weight loss [40].

The highest water absorption was shown by PLA $60 \%$ (8.1\%) and PLA $80 \%$ (7.8\%). This was because of a lack of material continuity due to the bulk region in the material, as observed in Figs. 1 and 2. PLA 100\% showed the greatest density of material and hence the lowest water absorption value $(\sim 1 \%)$. Because PLA is hygroscopic in nature, it can absorb approximately $1 \%$ water horizontally [35]. According to previous literature, lignocellulose-containing additives are susceptible to water absorption due to their hydrophilic nature (presence of many hydroxyl groups). The results of the present study also confirmed this fact. PLA/B (5.7\%) showed the highest water absorption in the group of lignocellulose fiber-reinforced composites. This is not only because of the strong hydrophilicity of PLA/B that has a significant impact on water absorption but also due to the fibers around which additional microchannel spaces are formed through which water can flow. In the group of composites reinforced with fillers, PLA/C $(4.28 \%)$ had the lowest water absorption rate. This relationship results from the cellulose content in the fibers. The higher the cellulose content, the higher the water absorption capacity. The content of cellulose in individual fillers used in the research is $40-50 \%$ for wood, $40-55 \%$ for bamboo, and $12-25 \%$ for cork, which corresponds to the results obtained in this study PLA/B $>$ PLA/W $>$ PLAC [41]. Moreover, higher water uptake capacity by wood than by cork has already been reported by other studies [34].

Figure 7 shows the results of tensile strength (a) and Young's modulus (b) after hydrodegradation of the composites. The tensile strength value for composites immersed for 28 days at $+38{ }^{\circ} \mathrm{C}$ decreased by approximately $5 \%$ and $20 \%$ for neat PLA and composites with natural particles, respectively. Lower decreases in the
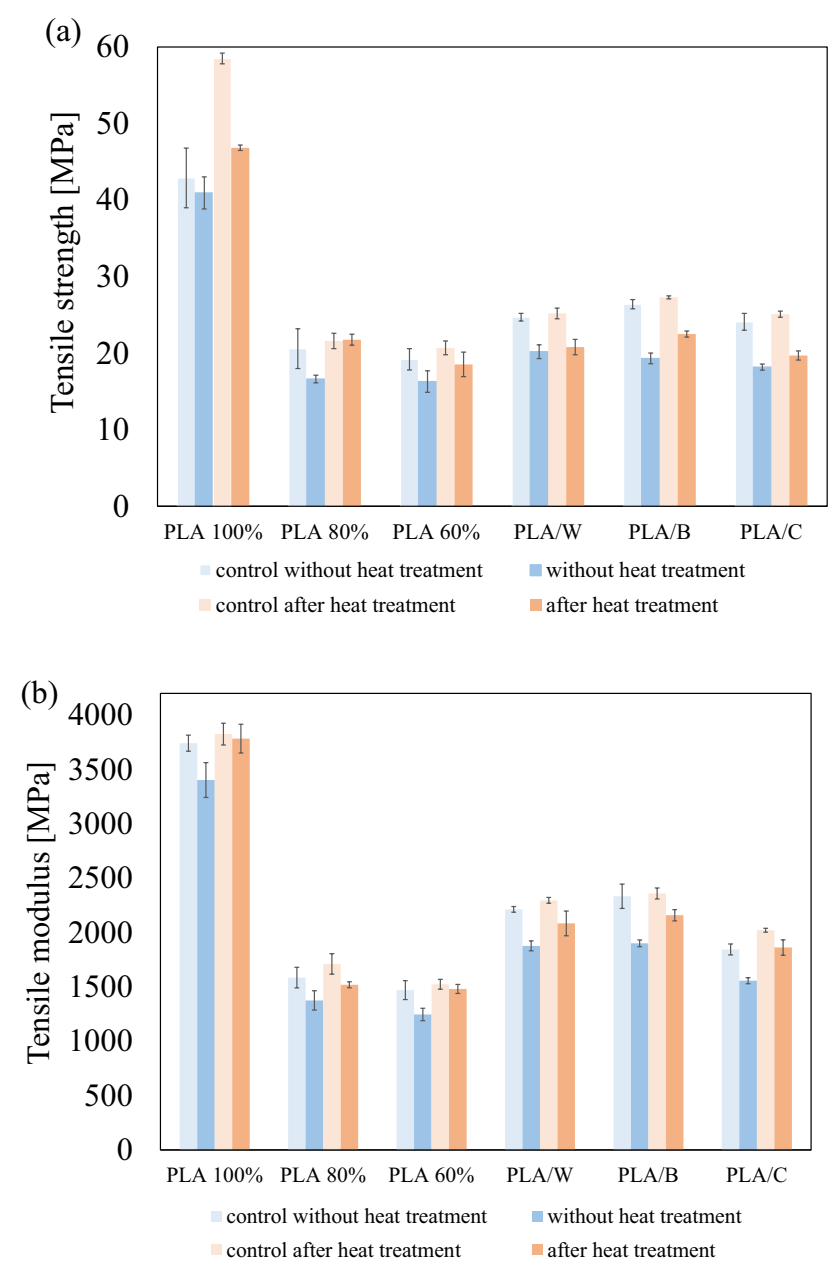

Fig. 7 Change of mechanical properties of samples immediately after printing (control) and after 28 days of hydrolytic degradation: a tensile strength and $\mathbf{b}$ Young's Modulus

mechanical properties of the neat polymer are associated with a greater ability to plastic deformation than for fiber-reinforced composites. Furthermore, natural fillers containing lignocellulose have a high water absorption capacity, which causes them to swell (increase in size), which contributes to the formation of cracks in the matrix [42]. In addition, water flowing into the material caused the fibers to detach from the matrix, which further contributed to the reduction of fiber/matrix adhesion. During the tensile test of materials subjected to water immersion, lignocellulosic fillers induce additional stress that reduces the values of mechanical properties (expansion and contraction of fibers during water absorption). However, in the case of Young's Modulus the decrease was about 10\% for heat treated materials. As mentioned earlier, composite stiffness is not as dependent on fiber adhesion as it is in tensile strength.

A similar tendency was observed for samples after heat treatment. By comparing the results obtained during tests at 
$80^{\circ} \mathrm{C}$, it can be concluded that biodegradable composites are more susceptible to high temperatures than to water. This is particularly evident for Young's Modulus, where neat PLA subjected to high temperature showed a decrease of approximately $90 \%$ at elevated temperatures.

\section{Conclusion}

The mechanical behavior of PLA-based composites in different states and conditions was investigated in this study. Studies have shown that both the effect of changing the amount of filling and the addition of natural fillers have a similar effect on mechanical properties. Heat treatment of manufactured composites increases their mechanical performance. Despite the decrease in mechanical properties after hydrolytic degradation, mechanical properties remain at a high level, which generates their potential use in long-term applications. In addition, the composites were characterized by high impact strength values comparable with neat PLA, and in the case of cork composites, improvement constituted $50 \%$.

In summary, the work presents the results obtained through the use of various techniques for the modification of biodegradable 3D printed materials. The obtained data will allow designing a material with the expected properties at an early stage of engineering design. As a result of the work, the impact of lignocellulosic particles has a different effect on the mechanical properties than in the case of injection-molded polymer composites. The addition of lignocellulosic fibers to injection-molded polymer composites generally improves their Young's modulus, while in the case of 3D printed composites it lowers their mechanical properties. However, the relatively high obtained mechanical properties compared to the density of composites with natural fillers and the low decrease in mechanical properties after hydrolytic degradation indicate their potential application in various industry sectors (medicine, furniture, decorations, automotive industry, and so on).

The presented results suggest in what direction should be guided further research on 3D printed polymer composites. It is important to increase the fiber adhesion to the matrix. This effect can be achieved by introducing smaller natural particles (nano or micro-scale) or by adding a plasticizer. With the addition of a plasticizer, one should consider the use of natural composition (leaving $100 \%$ biodegradable material) or the final use of material for engineering products whose $100 \%$ biodegradation is not required.

To sum up, the research presented in the paper shows how $3 \mathrm{D}$ printed polymer composites can be modeled by changing various components, i.e. type of filler, degree of filling, or rate of crystallization (pre or post-processing).

Author Contributions All authors contributed to the study conception and design. Material preparation, investigation and data collection were performed by KEM, AB, PK, SG, RB, DM and SK. The first draft of the manuscript was written by KEM and all authors commented on previous versions of the manuscript. All authors read and approved the final manuscript.

Funding This research did not receive any specific grant from funding agencies in the public, commercial, or not-for-profit sectors.

Data Availability The authors declare that they have no known competing financial interests or personal relationships that could have appeared to influence the work reported in this paper.

Code Availability The raw/processed data required to reproduce these findings cannot be shared at this time due to technical limitations. Specific (or example) data may be sent on request by the corresponding author.

\section{Declarations}

Conflict of interest The authors declare that they have no known competing financial interests or personal relationships that could have appeared to influence the work reported in this paper.

Open Access This article is licensed under a Creative Commons Attribution 4.0 International License, which permits use, sharing, adaptation, distribution and reproduction in any medium or format, as long as you give appropriate credit to the original author(s) and the source, provide a link to the Creative Commons licence, and indicate if changes were made. The images or other third party material in this article are included in the article's Creative Commons licence, unless indicated otherwise in a credit line to the material. If material is not included in the article's Creative Commons licence and your intended use is not permitted by statutory regulation or exceeds the permitted use, you will need to obtain permission directly from the copyright holder. To view a copy of this licence, visit http://creativecommons.org/licenses/by/4.0/.

\section{References}

1. Wang J, Li H, Liu R et al (2018) Thermoelectric and mechanical properties of PLA/Bi0.5Sb1.5Te3 composite wires used for 3D printing. Compos Sci Technol 157:1-9. https://doi.org/10.1016/j. compscitech.2018.01.013

2. Sang L, Han S, Li Z et al (2019) Development of short basalt fiber reinforced polylactide composites and their feasible evaluation for 3D printing applications. Composites Part B 164:629-639. https:// doi.org/10.1016/j.compositesb.2019.01.085

3. Bekas DG, Hou Y, Liu Y, Panesar A (2019) 3D printing to enable multifunctionality in polymer-based composites: a review. Composites Part B 179:107540. https://doi.org/10.1016/j.compositesb. 2019.107540

4. Cisneros-López EO, Pal AK, Rodriguez AU et al (2020) Recycled poly(lactic acid)-based 3D printed sustainable biocomposites: a comparative study with injection molding. Mater Today Sustain. https://doi.org/10.1016/j.mtsust.2019.100027 
5. Carlier E, Marquette S, Peerboom C et al (2019) Investigation of the parameters used in fused deposition modeling of poly(lactic acid) to optimize 3D printing sessions. Int J Pharm 565:367-377. https://doi.org/10.1016/j.ijpharm.2019.05.008

6. Yao T, Deng Z, Zhang K, Li S (2019) A method to predict the ultimate tensile strength of 3D printing polylactic acid (PLA) materials with different printing orientations. Composites Part B 163:393-402. https://doi.org/10.1016/j.compositesb.2019.01.025

7. Pyl L, Kalteremidou KA, Van Hemelrijck D (2018) Exploration of specimen geometry and tab configuration for tensile testing exploiting the potential of 3D printing freeform shape continuous carbon fibre-reinforced nylon matrix composites. Polym Test 71:318-328. https://doi.org/10.1016/j.polymertesting.2018.09.022

8. Yao T, Ye J, Deng Z et al (2020) Tensile failure strength and separation angle of FDM 3D printing PLA material: experimental and theoretical analyses. Composites Part B 188:107894. https:// doi.org/10.1016/J.COMPOSITESB.2020.107894

9. Kuo CC, Liu LC, Teng WF et al (2016) Preparation of starch/ acrylonitrile-butadiene-styrene copolymers (ABS) biomass alloys and their feasible evaluation for 3D printing applications. Composites Part B 86:36-39. https://doi.org/10.1016/j.compositesb. 2015.10.005

10. Velu R, Raspall F, Singamneni S (2019) 3D printing technologies and composite materials for structural applications. In: Green composites for automotive applications. pp 171-196

11. Sui T, Salvati E, Zhang H et al (2019) Probing the complex thermo-mechanical properties of a 3D-printed polylactidehydroxyapatite composite using in situ synchrotron X-ray scattering. J Adv Res 16:113-122. https://doi.org/10.1016/j.jare. 2018.11.002

12. Quiles-Carrillo L, Montanes N, Garcia-Garcia D et al (2018) Effect of different compatibilizers on injection-molded green composite pieces based on polylactide filled with almond shell flour. Composites Part B 147:76-85. https://doi.org/10.1016/j. compositesb.2018.04.017

13. Olewnik-Kruszkowska E, Burkowska-But A, Tarach I et al (2020) Biodegradation of polylactide-based composites with an addition of a compatibilizing agent in different environments. Int Biodeterior Biodegrad 147:104840. https://doi.org/ 10.1016/j.ibiod.2019.104840

14. Gil-Castell O, Badia JD, Ingles-Mascaros S et al (2018) Polylactide-based self-reinforced composites biodegradation: individual and combined influence of temperature, water and compost. Polym Degrad Stab 158:40-51. https://doi.org/10.1016/j.polym degradstab.2018.10.017

15. Fukushima K, Tabuani D, Dottori M et al (2011) Effect of temperature and nanoparticle type on hydrolytic degradation of poly(lactic acid) nanocomposites. Polym Degrad Stab 96:21202129. https://doi.org/10.1016/j.polymdegradstab.2011.09.018

16. Bismarck A, Aranberri-Askargorta I, Springer J et al (2002) Surface characterization of flax, hemp and cellulose fibers; surface properties and the water uptake behavior. Polym Compos 23:872-894. https://doi.org/10.1002/pc.10485

17. Lee D, Sun Y, Youe W-J et al (2021) 3D-printed wood-polylactic acid-thermoplastic starch composites: performance features in relation to biodegradation treatment. J Appl Polym Sci 138:50914. https://doi.org/10.1002/APP.50914

18. Fischer EW, Sterzel HJ, Wegner G (1973) Investigation of the structure of solution grown crystals of lactide copolymers by means of chemical reactions. Kolloid-Zeitschrift Zeitschrift für Polym 251:980-990. https://doi.org/10.1007/BF01498927

19. International Organization for Standardization (2012) ISO 5271:2012 - plastics—determination of tensile properties-Part 1: general principles

20. International Standards Organization (2011) ISO 178:2011plastics-determination of flexural properties
21. Lin T, Jia D, He P et al (2008) Effects of fiber length on mechanical properties and fracture behavior of short carbon fiber reinforced geopolymer matrix composites. Mater Sci Eng A 497:181-185. https://doi.org/10.1016/J.MSEA.2008.06.040

22. Mysiukiewicz O (2020) Barczewski M (2020) Crystallization of polylactide-based green composites filled with oil-rich waste fillers. J Polym Res 2712(27):1-17. https://doi.org/10.1007/ S10965-020-02337-5

23. Papadopoulos L, Klonos PA, Terzopoulou Z et al (2021) Comparative study of crystallization, semicrystalline morphology, and molecular mobility in nanocomposites based on polylactide and various inclusions at low filler loadings. Polymer (Guildf) 217:123457. https://doi.org/10.1016/J.POLYMER.2021.123457

24. Hao LC, Sapuan SM, Hassan MR, Sheltami RM (2018) Natural fiber reinforced vinyl polymer composites. In: Natural fibre reinforced vinyl ester and vinyl polymer composites. pp 27-70

25. Awal A, Rana M, Sain M (2015) Thermorheological and mechanical properties of cellulose reinforced PLA bio-composites. Mech Mater. https://doi.org/10.1016/j.mechmat.2014. 09.009

26. Gil-Castell O, Badia JD, Kittikorn T et al (2014) Hydrothermal ageing of polylactide/sisal biocomposites. Studies of water absorption behaviour and Physico-Chemical performance. Polym Degrad Stab 108:212-222. https://doi.org/10.1016/j.polymdegra dstab.2014.06.010

27. Kuciel S, Mazur K, Hebda M (2020) The influence of wood and basalt fibres on mechanical, thermal and hydrothermal properties of PLA composites. J Polym Environ. https://doi.org/10.1007/ s10924-020-01677-z

28. Lee KY, Bharadia P, Blaker JJ, Bismarck A (2012) Short sisal fibre reinforced bacterial cellulose polylactide nanocomposites using hairy sisal fibres as reinforcement. Compos Part A Appl Sci Manuf 43:2065-2074. https://doi.org/10.1016/j.compositesa. 2012.06.013

29. Furtos G, Silaghi-Dumitrescu L, Pascuta P, et al (2019) Mechanical properties of wood fiber reinforced geopolymer composites with sand addition. 18:285-296. https://doi.org/10.1080/15440 478.2019.1621792

30. Xiao X, Chevali VS, Song P et al (2019) Polylactide/hemp hurd biocomposites as sustainable 3D printing feedstock. Compos Sci Technol 184:107887. https://doi.org/10.1016/j.compscitech.2019. 107887

31. Bai H, Huang C, Xiu H et al (2014) Enhancing mechanical performance of polylactide by tailoring crystal morphology and lamellae orientation with the aid of nucleating agent. Polymer (Guildf) 55:6924-6934. https://doi.org/10.1016/j.polymer.2014.10.059

32. Kuciel S, Romańska P (2018) Hybrid composites of polylactide with basalt and carbon fibers and their thermal treatment. Materials (Basel). https://doi.org/10.3390/ma12010095

33. Arao Y, Fujiura T, Itani S, Tanaka T (2015) Strength improvement in injection-molded jute-fiber-reinforced polylactide greencomposites. Composites Part B 68:200-206. https://doi.org/10. 1016/j.compositesb.2014.08.032

34. Andrzejewski J, Szostak M, Barczewski M, Łuczak P (2019) Cork-wood hybrid filler system for polypropylene and poly(lactic acid) based injection molded composites. Structure evaluation and mechanical performance. Composites Part B 163:655-668. https://doi.org/10.1016/j.compositesb.2018.12.109

35. Cairncross, R. A.; Becker, J. G.; Ramaswamy, S.; O'Connor, R. Moisture Sorption, Transport, and Hydrolytic Degradation in Polylactide. Appl. Biochem. Biotechnol. 2006, 131 (1-3), 774-785. https://doi.org/10.1385/ABAB:131:1:774.

36. He ZL, Xu JK, Zhang L et al (2019) Dramatically enhanced tensile strength and impact toughness of polydicyclopentadiene composites by covalent bond formation between phenyl-functionalized 
silica and dicyclopentadiene. Composites Part B 170:31-40. https://doi.org/10.1016/j.compositesb.2019.04.040

37. Oksman K, Skrifvars M, Selin JF (2003) Natural fibres as reinforcement in polylactic acid (PLA) composites. Compos Sci Technol 63:1317-1324. https://doi.org/10.1016/S0266-3538(03) 00103-9

38. Valente M, Tirillò J, Quitadamo A, Santulli C (2017) Paper fiber filled polymer. Mechanical evaluation and interfaces modification. Composites Part B 110:520-529. https://doi.org/10.1016/j.compo sitesb.2016.11.013

39. Fick A (1855) Ueber diffusion. Ann Phys 94:59-86. https://doi. org/10.1002/andp.18551700105

40. Maslinda AB, Abdul Majid MS, Ridzuan MJM et al (2017) Effect of water absorption on the mechanical properties of hybrid interwoven cellulosic-cellulosic fibre reinforced epoxy composites.
Compos Struct 167:227-237. https://doi.org/10.1016/j.comps truct.2017.02.023

41. Fernandes EM, Pires RA, Mano JF, Reis RL (2013) Bionanocomposites from lignocellulosic resources: properties, applications and future trends for their use in the biomedical field. Prog Polym Sci 38:1415-1441. https://doi.org/10.1016/j.progpolymsci.2013. 05.013

42. Pickett JE (2018) Chapter 8 - Weathering of Plastics

Publisher's Note Springer Nature remains neutral with regard to jurisdictional claims in published maps and institutional affiliations. 